\title{
Heart Failure with Preserved Ejection Fraction-a Concise Review
}

\section{Daria M. Adamczak ${ }^{1}$ (D) Mary-Tiffany Oduah ${ }^{2} \cdot$ Thomas Kiebalo $^{2} \cdot$ Sonia Nartowicz $^{3} \cdot$ Marcin Bęben $^{3}$. Mateusz Pochylski ${ }^{3}$ - Aleksandra Ciepłucha ${ }^{1}$ • Adrian Gwizdała ${ }^{1}$ - Maciej Lesiak ${ }^{1}$ - Ewa Straburzyńska-Migaj ${ }^{1}$}

Published online: 9 July 2020

(C) The Author(s) 2020

\begin{abstract}
Purpose of Review Heart failure with preserved ejection fraction (HFpEF) is a relatively new disease entity used in medical terminology; however, both the number of patients and its clinical significance are growing. HFpEF used to be seen as a mild condition; however, the symptoms and quality of life of the patients are comparable to those with reduced ejection fraction. The disease is much more complex than previously thought. In this article, information surrounding the etiology, diagnosis, prognosis, and possible therapeutic options of HFpEF are reviewed and summarized.

Recent Findings It has recently been proposed that heart failure (HF) is rather a heterogeneous syndrome with a spectrum of overlapping and distinct characteristics. HFpEF itself can be distilled into different phenotypes based on the underlying biology. The etiological factors of HFpEF are unclear; however, systemic low-grade inflammation and microvascular damage as a consequence of comorbidities associated with endothelial dysfunction, oxidative stress, myocardial remodeling, and fibrosis are considered to play a crucial role in the pathogenesis of a disease. The $\mathrm{H}_{2} \mathrm{FPEF}$ score and the HFpEF nomogram are recently validated highly sensitive tools employed for risk assessment of subclinical heart failure.

Summary Despite numerous studies, there is still no evidence-based pharmacotherapy for HFpEF and the mortality and morbidity associated with HFpEF remain high. A better understanding of the etiological factors, the impact of comorbidities, the phenotypes of the disease, and implementation of machine learning algorithms may play a key role in the development of future therapeutic strategies.
\end{abstract}

Keywords $\mathrm{HFpEF} \cdot$ Heart failure $\cdot$ Diastolic dysfunction $\cdot$ Heart failure with preserved ejection fraction $\cdot$ Preserved left ventricular function

This article is part of the Topical Collection on Heart Failure

Daria M. Adamczak

daria.m.adamczak@gmail.com; daria.adamczak@skpp.edu.pl

Mary-Tiffany Oduah

dobezemd@gmail.com

Thomas Kiebalo

thomas.kiebalo@gmail.com

Sonia Nartowicz

sonianartowicz@gmail.com

Marcin Bęben

marcin398@gmail.com

Mateusz Pochylski

pochylskimateusz@gmail.com

Aleksandra Ciepłucha

ola.cieplucha@gmail.com
Adrian Gwizdała

adrian.gwizdala@gmail.com

Maciej Lesiak

maciej.lesiak@skpp.edu.pl

Ewa Straburzyńska-Migaj

ewa.straburzynska-migaj@skpp.edu.pl

1 Ist Department of Cardiology, Poznan University of Medical Sciences, Dluga Street 1/2, 61-848 Poznan, Poland

2 Center for Medical Education in English, Poznan University of Medical Sciences, Poznan, Poland

3 Faculty of Medicine, Poznan University of Medical Sciences, Poznan, Poland 


\section{Introduction}

The spectrum of disorders involving myocardial dysfunction with typical signs and symptoms has since been referred to as heart failure (HF) [1, 2]. Echocardiographic parameters, i.e., ejection fraction $(\mathrm{EF})$, have been used for subclassification of this complex clinical entity: heart failure with reduced EF (HFrEF; EF < 40\%), mid-range EF (HFmrEF; EF 41-49\%), and preserved $\mathrm{EF}$ (HFpEF; $\mathrm{EF} \geq 50 \%$ ) have all been recognized as different points on the continuum of heart failure disorders [3].

Heart failure has been increasingly recognized as an epidemic and various possible etiologies have now been identified. These include coronary artery disease, valvular heart disease, hypertension, cardiomyopathies, and adverse effects of drugs and toxins [3]. In developing and developed countries, heart failure incidence continues to rise, accounting for most cases of HF in the developed world [2, 3]. HFpEF was discovered by Dr. Luchi et al., who in 1982 described a group of patients with typical heart failure symptoms and associated preserved $(\geq 50 \%)$ left ventricular ejection fraction (LVEF) [4]. Recently, HFpEF has been defined by the European Society of Cardiology (ESC) as preserved left ventricular EF (LVEF $\geq 50 \%$ ), with evidence of diastolic dysfunction or structural heart disease, in the context of classic signs and symptoms of heart failure and elevated natriuretic peptides $[3,5]$.

The complex interplay between various factors involved in the etiopathogenesis and potentiation of heart failure has sparked a new drive for heart failure classification based on various (molecular and biochemical) parameters and biomarker profiles $[6,7 \bullet]$. Indeed, the inter- and intra-observer reliability of LVEF has been noted to vary markedly, thus diminishing the clinical utility of LVEF for diagnostic and prognostic purposes [7•]. However, the terms HFrEF, HFmrEF, and HFpEF will be used in our descriptions for simplicity.

\section{Prevalence and Demographics}

The prevalence of HF is estimated to be $1.1-5.5 \%$ in the general population [8]. It is a common cause of hospitalization. Those who are diagnosed with HFpEF represent about a third to one-half of the total number of HF patients [9-11]. Current data suggests that there is a shift in the type of heart failure patients are likely to be diagnosed with. Epidemiological data revealed that the prevalence of $\mathrm{HFpEF}$ relative to $\mathrm{HFrEF}$ is increasing at a rate of $1 \%$ per year, indicating that $\mathrm{HFpEF}$ is becoming the most common type of $\mathrm{HF}$ [8]. The highest rate of HFpEF is among the elderly; however, the younger subgroup of patients ( $<65$-year-old) accounts for $40 \%$ of all total cases $[9,12]$. HFpEF affects more women than men, suggesting that gender may play a major role in disease evolution [13]. On the other hand, incidence rates are similar across all races and ethnicities [14]. Although patients with HFpEF have a lower risk of death than patients with HFrEF (HR 0.62, 95\% CI 0.46-0.85), regardless of age, gender, or etiology of HF, absolute mortality is still high [15].

\section{Etiology}

The etiology and pathophysiology of HFpEF are still being uncovered. Firstly, the etiological factors affecting HFpEF and HFrEF seem to be different [16]. The Framingham Heart Study suggests that the classification of HF be made depending on the underlying cause of the disease: coronary artery disease, valvular heart disease, hypertension, or other causes $[16,17]$. Patients with HFpEF are more likely to have valvular heart disease, hypertension, and atrial fibrillation $(p=0.05$, $p<0.001$, and $p<0.001$, respectively). On the contrary, patients with $\mathrm{HFpEF}$ are less likely to have a myocardial infarction or left bundle branch block (LBBB) (OR 0.21, 95\% CI, $0.10-0.46, p<0.001)$. Compared to patients with HFrEF, patients with HFpEF have significantly higher blood pressure $(p=0.04)$, lower resting heart rate, and lower levels of potassium in the plasma [16]. Many studies point out that patients with HFpEF are usually older women with hypertension $[15$, $16,18,19]$. Indeed, arterial hypertension is one of the main factors leading to increased stiffness of blood vessels and increased afterload of LV [20].

Furthermore, comorbidities seem to play a pivotal role in the pathophysiology of HFpEF. The most common are obesity, diabetes, atrial fibrillation, metabolic syndrome, chronic obstructive pulmonary disease, sleep-disordered breathing, renal dysfunction, and anemia [7•,21-27]. Aging seems to have a great impact as well $[10,28,29]$.

Although the pathophysiology of HFpEF is yet to be understood, systemic low-grade inflammation, mediated through tumor necrosis factor (TNF) alpha and transforming growth factor (TGF) beta 1, was proposed as a cause of disease $[18,30]$. However, the degree of diffuse myocardial fibrosis is not related to the severity of impairment of diastolic function in HFpEF [31]. Microvascular dysfunction induces systemic inflammation which is present before the clinical symptoms [18, 32]. It is mediated by microRNAs and the formation of different miRNA [18, 33]. Furthermore, the intrinsic cardiomyocyte phenotype is distinct in HFpEF and HFrEF. Research by Curl et al. indicates that hypertrophic heart rat (HHR) shows a significantly elevated calcium $\left(\mathrm{Ca}^{2+}\right)$ operating level and increased L-type calcium channel current, which contrasts with the suppressed $\mathrm{Ca}^{2+}$ cycling state typical for HFrEF [34]. 


\section{Clinical Manifestations}

The initial presenting symptoms of HFpEF may be included in the broad category of heart failure. Dyspnea is the most common manifesting symptom among them. Shortness of breath can manifest in various ways, whether it be upon exertion or at rest as in paroxysmal nocturnal dyspnea or orthopnea. Other non-specific symptoms such as fatigue are present. The typical heart failure symptoms such as ankle edema and jugular venous distention are often not present. Other possible presentations include decreased exercise tolerance, chest pain, or discomfort.

\section{Diagnosis}

The $\mathrm{H}_{2}$ FPEF score and the HFpEF nomogram are recently validated highly sensitive tools employed for risk assessment of subclinical heart failure. These tools are based on clinical and echocardiographic parameters, including body mass in$\operatorname{dex}(\mathrm{BMI})>30 \mathrm{~kg} / \mathrm{m}^{2}(\mathrm{H})$; use of 2 or more antihypertensive medications $(\mathrm{H})$; the presence of atrial fibrillation $(\mathrm{F})$; pulmonary hypertension (pulmonary artery systolic pressure $>$ $35 \mathrm{mmHg}$ ) (P); elderly with an age $>60$ years $(\mathrm{E})$; and elevated filling pressures $\left(E / e^{\prime}>9\right)(\mathrm{F})$. The $\mathrm{H}_{2} \mathrm{FPEF}$ score determines the probability of HFpEF by assigning a number for each item (Fig. 1) [35•]. Although formerly designated as heart failure with diastolic dysfunction, HFpEF may occur in the absence of signs of diastolic dysfunction, and as such evidence/presence of diastolic dysfunction is not required for the diagnosis [36].

As previously mentioned, the European Society of Cardiology (ESC) guidelines for the diagnosis of HFpEF include left ventricular EF (LVEF) $\geq 50 \%$, evidence of either diastolic dysfunction or structural heart disease, signs and/or symptoms of heart failure, and elevated natriuretic peptides [3]. Given the complexity of HFpEF, various parameters including clinical (patient history and physical examination), biochemical (serum BNP level), hemodynamic, and radiographic data are utilized in reaching a diagnosis [37, 38]. Oftentimes exercise testing is required to confirm the diagnosis when signs of diastolic dysfunction occur only on exertion but not at rest. Nevertheless, the echocardiographic evaluation is crucial, and advanced techniques seem particularly promising. Shah et al. proposed recently that echocardiography could serve as a "digital biopsy" of the heart. Speckle-tracking echocardiography (STE) can be utilized to assess cardiomyocyte calcium homeostasis, excitation-contraction coupling, and the health of T-tubules before the onset of myocardial fibrosis [39, 40]. Furthermore, defining left atrial structure and function has recently gained importance in evaluation of LV diastolic dysfunction [41].

$$
\mathrm{H}=\text { Heavy }=\text { BMI }>30 \mathrm{~kg} / \mathrm{m} 2=2 \mathrm{pts}
$$

$\mathrm{H}=$ Hypertension $=\mathbf{1} \mathbf{p t}$

( $\geq 2$ antiHypertensive medications)

$\mathrm{F}=\uparrow$ Filling $=1$ pt
pressures $\left(\mathrm{E} / \mathrm{e}^{\prime}>9\right)$

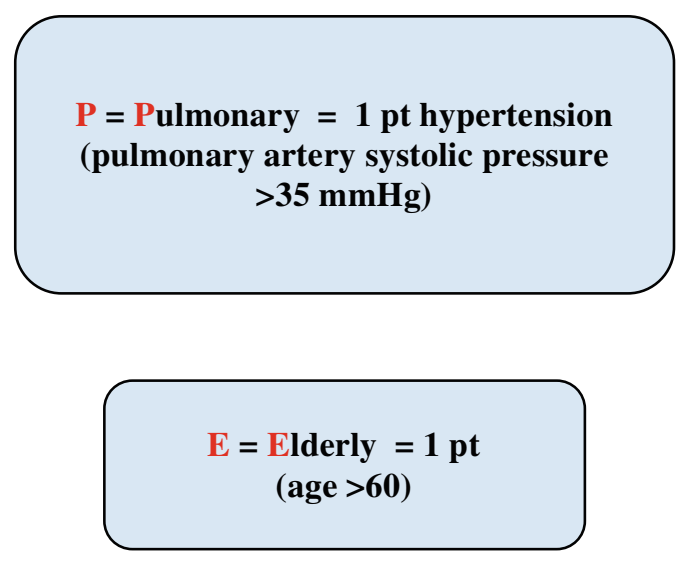

$\mathrm{F}=$ paroxysmal or persistent $=\mathbf{3} \mathrm{pts}$ atrial Fibrillation

Fig. $1 \mathrm{H}_{2}$ FPEF score used to determine the probability of HFpEF (figure created based on text from Paulus [35•])

Since HFpEF may also share similar clinical characteristics with valvular heart disease, pericardial disease, and highoutput HF [42], diagnostic algorithms are useful in making the diagnosis of HFpEF (Fig. 2).

\section{HFpEF Phenotypes}

Phenotypic presentations of HFpEF may vary widely across patients and determine the choice of diagnostic tests and targeted management plan [39・•, 43-46]. There are four 
Fig. 2 Diagnostic algorithm for $\mathrm{HFpEF}$ (figure created based on text from Huis in't Veld et al. [38])

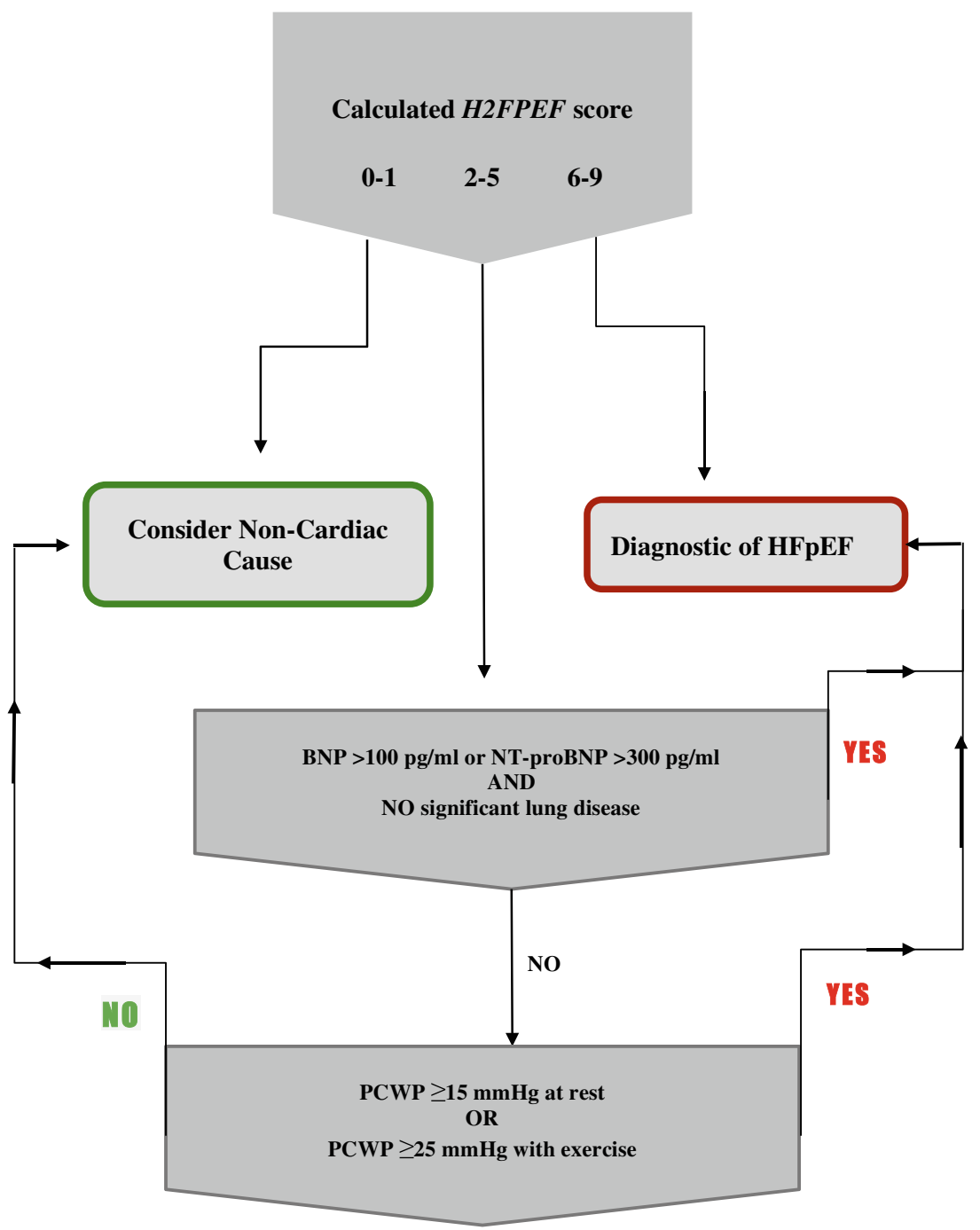

clinically distinct phenotypes of HFpEF that have been recognized [47]:

- Aging phenotype

- Obesity phenotype

- Pulmonary hypertension (PH) phenotype

- Coronary artery disease (CAD) phenotype

Although this classification acknowledges the heterogeneity and need for individualized approach, the biological phenotypes seem to better describe the underlying pathomechanisms of HFpEF. Shah et al. proposed a classification created by the use of machine learning [39••, 45, 48]:

The three identified biological phenogroups are as follows:

1. Natriuretic peptide deficiency syndrome-younger subjects with moderate diastolic dysfunction and relatively normal BNP

2. Extreme cardiometabolic syndrome —obese, diabetic subjects with a high prevalence of obstructive sleep apnea
3. Right ventricle-cardio-abdomino-renal syndrome - older subjects with significant chronic kidney disease and cardiopulmonary comorbidities

Worse outcomes are observed in phenogroups 2 and 3.

It is generally thought that the heterogeneity in the clinical presentation of HFpEF may be explained by underlying comorbidities in individual subjects. Thus, phenogrouping enables risk stratification and the institution of better-targeted therapies as opposed to BNP-based stratification alone [45].

\section{Differential Diagnosis}

Since symptoms of HFpEF are non-specific, diagnosis might be elusive. The majority of patients complain of exertional dyspnea, which is a common cause of hospital admission. As such, there are multiple differential diagnoses to consider, including pulmonary and cardiovascular causes, or vocal cord conditions [49]. Differential diagnosis to rule out other causes 
of dyspnea should be based on echocardiographic examination and tissue doppler imaging [50]. Overall, clinicians should pay attention to non-specific manifestations of HFpEF and diagnose sensibly based on imaging studies.

\section{Evaluation of Comorbidities}

In recent years, a new paradigm of HFpEF has been suggested, implying that it is a very heterogeneous disease. It can be caused by comorbidities through systemic endothelial inflammation leading to structural and functional remodeling of the heart [51].

The most significant comorbidities are obesity, diabetes, metabolic syndrome, chronic obstructive pulmonary disease, sleep-disordered breathing, renal dysfunction, and anemia [7•, 21-27]. Excess visceral fat leads to increased levels of proinflammatory cytokines [52]. Hyperglycemia, hyperinsulinemia, and insulin resistance lead to mitochondrial and microvascular dysfunction, as well as autonomic neuropathy, which cause cardiac stiffness, hypertrophy, fibrosis, and eventually HF [53]. It is worth noting that proper diagnosis and an understanding of comorbidities can significantly contribute to improvement in HFpEF patients' outcomes [27].

\section{HFpEF and Hypertension}

Chronic maladaptive neurohumoral activation leading to sustained systemic arterial hypertension has been implicated in the course of HFpEF [54]. Studies have shown that systemic hypertension is a critical determinant of outcome in HFpEF as it plays a crucial role in the onset and maintenance of a proinflammatory state, arterial stiffness, ventricular hypertrophy, titin-dependent stiffness, and dysfunction [55-57]. In patients with HFpEF, control of hypertension can induce regression of myocardial mass and improve cardiac function and relaxation as well as clinical outcomes [58, 59]. Thus, if concomitant hypertensive disease exists, it is crucial to introduce medical therapy in order to achieve lower blood pressure targets and prevent the untoward complications of increased afterload [56, 60]. According to ALLHAT trial, HFpEF patients have a more favorable prognosis than HFrEF counterparts, even among high-risk hypertensive patients [61, $62]$.

\section{HFpEF and Amyloidosis}

Two types of amyloid commonly infiltrate the myocardiumimmunoglobulin light chain (AL or primary systemic) amyloid and transthyretin (TTR) amyloid. Transthyretin-related amyloidoses (ATTR) may be either hereditary (caused by autosomal dominant mutations in the TTR gene) or acquired (due to misaggregation of wild-type transthyretin). ATTR amyloidosis is an increasingly common cause of HFpEF and must be excluded in patients suspected of HF $[63,64]$. The amyloid is deposited in the myocardium and/or peripheral nervous system [65]. The most common cardiac symptoms are dyspnea, angina, edema, and syncope [66]. Non-cardiac manifestations include peripheral neuropathy, characterized by symptoms of neuropathic pain, numbness, and loss of muscle strength in the lower extremities. Gastrointestinal symptoms such as diarrhea and weight loss result as a consequence of autonomic neuropathy or autonomic nerve dysfunction of unknown etiology $[67,68]$. Other autonomic manifestations include erectile dysfunction, orthostatic hypotension, and neurogenic bladder [69]. In addition, symptoms such as lumbar spinal stenosis may appear [70, 71]. Distal biceps tendon spontaneous rupture is also common in patients with transthyretin cardiac amyloidosis [72]. Ando et al. have also reported vitreous body inclusions of the cotton wool type, which are pathognomonic for ATTR amyloidosis [69]. Carpal tunnel syndrome (CTS) is an early presenting sign of disease, preceding the onset of HF by up to 5-9 years [73]. The prevalence of ATTR amyloidosis among patients with CTS is $7-8 \%$, compared to $4-5 \%$ in the general population $[74,75]$. CTS manifests as pain and sensory disturbances in the lateral distribution of the hand, as well as hand weakness observed in cases of severe focal neuropathy [76]. Biopsy and histopathologic analysis used to be required to identify amyloidosis. Congo red or Direct Fast Scarlet 4BS staining binds to amyloid fibrils and characteristic apple-green birefringence under polarized light microscopy is noted. However, imaging techniques as well as genetic testing are becoming increasingly important [77-79]. Echocardiography and cardiac magnetic resonance may reveal features suggestive of amyloidosis, such as thickened LV wall, atrial septum and valves, small LV cavity size, biatrial enlargement, elevated RV systolic pressure, granular sparkling appearance of the myocardial wall, pericardial effusion, restrictive filling pattern, and reduced ventricular strain with relative apical sparing pattern. However, it is not sufficient for the diagnosis [80-83]. Nuclear imaging techniques employing technetium-99 $\left({ }^{99 \mathrm{~m}} \mathrm{Tc}\right)$ labeled diphosphonopropanodicarboxylic acid $\left({ }^{99 \mathrm{~m}} \mathrm{Tc}-\mathrm{DPD}\right)$, pyrophosphate $\left({ }^{99 \mathrm{~m}} \mathrm{Tc}-\mathrm{PYP}\right)$, or methylenediphosphonic acid $\left({ }^{99 \mathrm{~m}} \mathrm{Tc}-\mathrm{MDP}\right)$, once used as a bone scintigraphy, provide a novel, non-invasive diagnostic approach with relatively high sensitivity $(>90 \%)$ and specificity $(86 \%)[84,85]$. Intense uptake of ${ }^{99 \mathrm{~m}} \mathrm{Tc}$-DPD in the myocardium with lower or absent uptake in the bones suggests ATTR amyloidosis. Positive bone scintigraphy in patients without monoclonal gammopathy characterizes $100 \%$ specificity [86]. It enables to establish the diagnosis without the need of histology [84]. 


\section{Treatment}

There is no evidence that medications, which are known to be effective at alleviating symptom burden and reducing mortality in patients with HFrEF, are equally effective for patients with HFpEF. It may be due to the disparateness of the disease as well as multifactorial pathophysiology of the disease [87]. The number of available clinical trials on the treatment of $\mathrm{HFpEF}$ is finite. Currently, angiotensin-converting enzyme blockers (ACEIs), angiotensin receptor blockers (ARBs), calcium channel blockers (CCBs), and beta-blockers are given to these patients, although trials with perindopril, candesartan, irbesartan, and nebivolol did not show a clear advantage over placebo [88-93]. On the contrary, spironolactone may be effective in HFpEF treatment. The TOPCAT randomized double-blinded study had as its aim to determine what effect spironolactone would have on HFpEF in regard to mortality. It was found that it did not impact the time until first hospitalization for HF exacerbation nor did it have an influence on mortality. Post hoc analysis of the TOPCAT study showed however that the hospitalization rate of patients randomized to spironolactone was reduced by $17 \%$. The authors of the study go on to state that clinicians wanting to utilize spironolactone in the subpopulation of HF patients should be cognizant of the potential for hyperkalemia and increased serum creatinine, necessitating regular monitoring while on therapy [94]. Although sacubitril/valsartan is highly beneficial in the treatment of HFrEF patients, the PARAGON-HF trial revealed that it does not significantly lower the rate of total hospitalizations for heart failure and death from cardiovascular causes among these patients [95]. It has been hypothesized that the administration of short-term nitrate or inorganic nitrite may promote nitric oxide signaling, thus enhancing aerobic ability in patients with HFpEF. However, the administration of inhaled inorganic nitrite for 4 weeks, compared to placebo, also did not result in significant improvement in exercise capacity [96]. On the other hand, according to Nochioka et al., the treatment of HFpEF with statins reduces mortality [97]. Recent data reveal that anti-diabetic and anti-inflammatory drugs, anti-fibrotic and high-density lipoprotein-raising strategies, microRNases, mitochondrial-targeted anti-oxidants, and therapeutic options may be promising, although these warrant further investigations [98].

Interestingly, therapy with chlorthalidone has been found to prevent the occurrence of new-onset HFpEF in hypertensive patients [61]. Furthermore, in those subjects, ACEIs have shown promising results, namely lower blood pressure, decreased frequency of HF-related hospitalizations, improved exercise capacity, and diastolic function [56, 99].

The treatment of TTR amyloidosis is based on tafamidis, a drug that has been approved for use in patients with TTR polyneuropathy. In this condition, it has a significant impact on reducing symptoms and stabilizing TTR tetramers, and has been well-tolerated [100]. Findings from the ATTR-ACT study on ATTR cardiomyopathy show that tafamidis is associated with reduced mortality and cardiovascular-related hospitalizations. There are major benefits from the treatment if used in the early stage of the disease because of a reduction in the decline in functional capacity [101].

Emphasis is now being placed on the benefit of exercise therapy for patients with heart failure. This is in direct response to exercise intolerance being the primary symptom of patients with chronic $\mathrm{HF}$ and a major factor decreasing quality of life (QOL) in these patients [102]. Studies comparing endurance training in patients with HFpEF and HFrEF have shown a $19 \%$ improvement in peak $\mathrm{VO}_{2}$ in $\mathrm{HFpEF}$ after 12 weeks of exercise therapy. In contrast, no improvement was observed in the group with HFrEF [103]. The InterAtrial Shunt Device (IASD $\left.{ }^{\circledR}\right)$, which reduces the elevated left atrial pressures, may also be promising [104, 105].

Due to the complex pathophysiology of HFpEF, multiple treatment strategies are still needed and will be required to target specific mechanisms of disease. As described in the Framingham Heart and the Cardiovascular Health Studies, the incidence of HFrEF has been declining $(p=0.0029)$, while the incidence of HFpEF is on the rise $(p<0.001)$. These trends were noticed from 1990 to 2009 [106]. It is necessary to discover the pathomechanisms responsible for this divergent trend. Until we are familiar with the pathways involved in this multifactorial disease, we can only recommend medications for our patients, which are known to work in other subtypes of HF. Needless to say, therefore, the treatment of comorbidities is of utmost importance. Recent data suggest that heart failure disease management programs may improve mortality, number of hospitalizations, self-care, and quality of life $[107,108]$. However, it must be emphasized that there is currently no evidence-based therapy for HFpEF [109].

\section{Prognosis}

Some sources report that both HF groups have similar outcomes, prognosis, and survival $[8,9,110,111]$. On the contrary, the other studies point out that patients with HFpEF have a much better prognosis than patients with $\operatorname{HFrEF}[112,113]$. Somaratne et al. suggest that the survival rate of people with $\mathrm{HFpEF}$ is 50\% higher compared to patients with HFrEF [114]. Although survival in HFrEF has significantly improved over the past decade, the prognosis of patients with HFpEF has not shown any notable change within the same time period despite the use of similar pharmacotherapy. The annual mortality of HFpEF patients in the USA is $8-12 \%$ [115]. In a major observational study, 5-year survival rate of HFpEF patients after hospitalization for HF was only 35-40\%. Lack of evidencebased therapeutic strategies may play a pivotal role in curbing high rates of mortality and morbidity in HFpEF [8]. 
The identified prognostic factors in patients with $\mathrm{HFpEF}$ are as follows:

- Cystatin C (high serum level confers worse prognosis)

- B-type natriuretic peptide

- NT-proBNP

- Diabetes

- Growth factor 15 (GDF-15) [116-123]

Compared to patients with $\mathrm{HFrEF}$, patients with $\mathrm{HFpEF}$ show lower levels of both B-type natriuretic peptide and NTproBNP. However, in both cases, they are an important prognostic factor [123, 124]. Factors such as reduced LV compliance and remodeling of right ventricle (RV) also have prognostic significance, adversely affecting the prognosis [125]. Other factors that worsen prognosis are the coexistence of ischemic heart disease, diabetes mellitus, and chronic renal failure $[22,126]$.

\section{Summary}

Heart failure with preserved ejection fraction (HFpEF) is defined by a left ventricular ejection fraction $\geq 50 \%$ in the presence of clinical signs and/or symptoms of heart failure, diastolic dysfunction, or structural abnormality of the left ventricle (LV). However, the system of classifying HF according to LVEF has been recently challenged. Symptoms classically associated with HF include dyspnea, paroxysmal nocturnal dyspnea, orthopnea, and fatigue. Natriuretic peptides are elevated.

The most common underlying causes of the disease are coronary artery disease, valvular heart disease, and hypertension, while the most common comorbidities in this population include obesity, diabetes, atrial fibrillation, metabolic syndrome, chronic obstructive pulmonary disease, sleepdisordered breathing, renal dysfunction, and anemia. Amyloidosis, specifically ATTR amyloidosis, is also an increasingly common cause of HFpEF and must be excluded in patients suspected of HF. While the pathophysiology of HFpEF is still being uncovered, the role of systemic lowgrade inflammation and microvascular damage related to endothelial dysfunction, oxidative stress, and myocardial remodeling and fibrosis seem to be important components. As the percentage of HFpEF grows, relative to all cases of HF, it is a diagnosis, which clinicians need to be cognizant of.

Due to the fact that several pathophysiological processes may lead to dyspnea, the differential diagnosis is necessary to exclude the non-cardiac etiologies. Not all cases of HFpEF will present acutely. To screen for subclinical heart failure risk, the $\mathrm{H}_{2}$ FPEF score and the HFpEF nomogram may be utilized. As there may be other diseases that mimic or share clinical characteristics, diagnostic algorithms are useful in making the diagnosis of HFpEF. The existence of different phenotypes of HFpEF becomes important when deciding which diagnostic strategies to employ.

Currently there is no proven pharmacotherapy specifically for HFpEF. Current pharmacotherapy includes angiotensinconverting enzyme inhibitors/aldosterone receptor blockers (ACE-inhibitors/ARBs), calcium channel blockers (CCBs), and beta-blockers. These medications are being used among HFpEF patients because of the high cardiovascular risk and concomitant diseases seen in this population. Treatment with spironolactone, however, seems to be promising. Finally, exercise therapy is being studied for its possible role in the treatment of these patients.

Due to a lack of evidence-based treatment strategies for HFpEF, the mortality and morbidity associated with the disease have remained high. The 5-year survival rate among patients with $\mathrm{HFpEF}$ is $35-40 \%$ after hospitalization. Further studies, especially with the use of machine learning, are warranted to investigate other underlying processes that lead to HFpEF as well as targeted pharmacotherapy for patients with HFpEF.

\section{Compliance with Ethical Standards}

Conflict of Interest The authors declare that they have no conflict of interest.

Human and Animal Rights and Informed Consent This article does not contain any studies with human or animal subjects performed by any of the authors.

Open Access This article is licensed under a Creative Commons Attribution 4.0 International License, which permits use, sharing, adaptation, distribution and reproduction in any medium or format, as long as you give appropriate credit to the original author(s) and the source, provide a link to the Creative Commons licence, and indicate if changes were made. The images or other third party material in this article are included in the article's Creative Commons licence, unless indicated otherwise in a credit line to the material. If material is not included in the article's Creative Commons licence and your intended use is not permitted by statutory regulation or exceeds the permitted use, you will need to obtain permission directly from the copyright holder. To view a copy of this licence, visit http://creativecommons.org/licenses/by/4.0/.

\section{References}

Papers of particular interest, published recently, have been highlighted as:

- Of importance

- Of major importance

1. Savarese G, Lund LH. Global public health burden of heart failure. Card Fail Rev. 2017;3:7-11. https://doi.org/10.15420/cfr. 2016:25:2 
2. Ziaeian B, Fonarow GC. Epidemiology and aetiology of heart failure. Nat Rev Cardiol. 2016;13:368-78. https://doi.org/10. 1038/nrcardio.2016.25.

3. Ponikowski P, Voors AA, Anker SD, Bueno H, Cleland JGF, Coats AJS, et al. 2016 ESC Guidelines for the diagnosis and treatment of acute and chronic heart failure: The Task Force for the diagnosis and treatment of acute and chronic heart failure of the European Society of Cardiology (ESC)Developed with the special contribution of the Heart Failure Association (HFA) of the ESC. Eur Heart J. 2016;37:2129-200. https://doi.org/10. 1093/eurheartj/ehw128.

4. Luchi RJ, Snow E, Luchi JM, Nelson CL, Pircher FJ. Left ventricular function in hospitalized geriatric patients. J Am Geriatr Soc. 1982;30:700-5. https://doi.org/10.1111/j.1532-5415.1982. tb01983.x.

5. Webb J, Fovargue L, Tøndel K, Porter B, Sieniewicz B, Gould J, et al. The emerging role of cardiac magnetic resonance imaging in the evaluation of patients with HFpEF. Current Heart Failure Reports. 2018;15:1-9. https://doi.org/10.1007/s11897-018-03721.

6. Singh A, Mehta Y. Heart failure with preserved ejection fraction (HFpEF): implications for the anesthesiologists. J Anaesthesiol Clin Pharmacol. 2018;34:161-5. https://doi.org/10.4103/joacp. JOACP 35216.

7. Triposkiadis F, Butler J, Abboud FM, Armstrong PW, Adamopoulos S, Atherton JJ, et al. The continuous heart failure spectrum: moving beyond an ejection fraction classification. Eur Heart J. 2019;40:2155-63. https://doi.org/10.1093/eurheartj/ ehz158 In this study, the authors challenge the paradigm of classifying HF according to LVEF and propose that HF is a heterogeneous syndrome.

8. Owan TE, Hodge DO, Herges RM, Jacobsen SJ, Roger VL, Redfield MM. Trends in prevalence and outcome of heart failure with preserved ejection fraction. N Engl J Med. 2006;355:251-9. https://doi.org/10.1056/NEJMoa052256.

9. Abebe TB, Gebreyohannes EA, Tefera YG, Abegaz TM. Patients with HFpEF and HFrEF have different clinical characteristics but similar prognosis: a retrospective cohort study. BMC Cardiovasc Disord. 2016;16. https://doi.org/10.1186/s12872-016-0418-9.

10. Borlaug BA, Paulus WJ. Heart failure with preserved ejection fraction: pathophysiology, diagnosis, and treatment. Eur Heart J. 2011;32:670-9. https://doi.org/10.1093/eurheartj/ehq426.

11. Edelmann F. Facts and numbers on epidemiology and pharmacological treatment of heart failure with preserved ejection fraction. ESC Heart Fail. 2015;2:41-5. https://doi.org/10.1002/ehf2.12037.

12. Dunlay SM, Roger VL, Redfield MM. Epidemiology of heart failure with preserved ejection fraction. Nat Rev Cardiol. 2017;14:591-602. https://doi.org/10.1038/nrcardio.2017.65.

13. Duca F, Zotter-Tufaro C, Kammerlander AA, Aschauer S, Binder $\mathrm{C}$, Mascherbauer J, et al. Gender-related differences in heart failure with preserved ejection fraction. Sci Rep. 2018;8:1080. https:// doi.org/10.1038/s41598-018-19507-7.

14. Silverman MG, Patel B, Blankstein R, Lima JAC, Blumenthal RS, Nasir K, et al. Impact of race, ethnicity, and multimodality biomarkers on the incidence of new-onset heart failure with preserved ejection fraction (from the Multi-Ethnic Study of Atherosclerosis). Am J Cardiol. 2016;117:1474-81. https://doi.org/10.1016/j. amjcard.2016.02.017.

15. Meta-analysis Global Group in Chronic Heart Failure (MAGGIC). The survival of patients with heart failure with preserved or reduced left ventricular ejection fraction: an individual patient data meta-analysis. Eur Heart J. 2012;33:1750-7. https:// doi.org/10.1093/eurheartj/ehr254

16. Lee DS, Gona P, Vasan RS, Larson MG, Benjamin EJ, Wang TJ, et al. Relation of disease pathogenesis and risk factors to heart failure with preserved or reduced ejection fraction: insights from the Framingham Heart Study of the National Heart, Lung, and Blood Institute. Circulation. 2009;119:3070-7. https://doi.org/10. 1161/CIRCULATIONAHA.108.815944.

17. Ho KK, Anderson KM, Kannel WB, Grossman W, Levy D. Survival after the onset of congestive heart failure in Framingham Heart Study subjects. Circulation. 1993;88:107-15. https://doi.org/10.1161/01.CIR.88.1.107.

18. Rech M, Barandiarán Aizpurua A, van Empel V, van Bilsen M, Schroen B. Pathophysiological understanding of HFpEF: microRNAs as part of the puzzle. Cardiovasc Res. 2018;114: 782-93. https://doi.org/10.1093/cvr/cvy049.

19. Reddy YNV, Carter RE, Obokata M, Redfield MM, Borlaug BA. A simple, evidence-based approach to help guide diagnosis of heart failure with preserved ejection fraction. Circulation. 2018;138:861-70. https://doi.org/10.1161/CIRCULATIONAHA. 118.034646 .

20. Mayet J, Hughes A. Cardiac and vascular pathophysiology in hypertension. Heart. 2003;89:1104-9. https://doi.org/10.1136/ heart.89.9.1104.

21. Unger ED, Dubin RF, Deo R, Daruwalla V, Friedman JL, Medina $\mathrm{C}$, et al. Association of chronic kidney disease with abnormal cardiac mechanics and adverse outcomes in patients with heart failure and preserved ejection fraction: CKD and cardiac mechanics in HFpEF. Eur J Heart Fail. 2016;18:103-12. https://doi.org/ 10.1002/ejhf.445.

22. Kristensen SL, Mogensen UM, Jhund PS, Petrie MC, Preiss D, Win S, et al. Clinical and echocardiographic characteristics and cardiovascular outcomes according to diabetes status in patients with heart failure and preserved ejection fraction: a report from the I-Preserve Trial (Irbesartan in Heart Failure With Preserved Ejection Fraction). Circulation. 2017;135:724-35. https://doi.org/ 10.1161/CIRCULATIONAHA.116.024593.

23. Lindman BR, Dávila-Román VG, Mann DL, McNulty S, Semigran MJ, Lewis GD, et al. Cardiovascular phenotype in HFpEF patients with or without diabetes. J Am Coll Cardiol. 2014;64:541-9. https://doi.org/10.1016/j.jacc.2014.05.030.

24. Hunt SA, Abraham WT, Chin MH, Feldman AM, Francis GS, Ganiats TG, et al. ACC/AHA 2005 guideline update for the diagnosis and management of chronic heart failure in the adult: a report of the American College of Cardiology/American Heart Association Task Force on Practice Guidelines (Writing Committee to Update the 2001 Guidelines for the Evaluation and Management of Heart Failure): developed in collaboration with the American College of Chest Physicians and the International Society for Heart and Lung Transplantation: endorsed by the Heart Rhythm Society. Circulation. 2005;112: e154-235. https://doi.org/10.1161/CIRCULATIONAHA.105. 167586.

25. Redfield MM, Jacobsen SJ, Burnett JC, Mahoney DW, Bailey KR, Rodeheffer RJ. Burden of systolic and diastolic ventricular dysfunction in the community: appreciating the scope of the heart failure epidemic. JAMA. 2003;289:194-202. https://doi.org/10. 1001/jama.289.2.194.

26. Zafrir B, Lund LH, Laroche C, Ruschitzka F, Crespo-Leiro MG, Coats AJS, et al. Prognostic implications of atrial fibrillation in heart failure with reduced, mid-range, and preserved ejection fraction: a report from 14964 patients in the European Society of Cardiology Heart Failure Long-Term Registry. Eur Heart J. 2018;39:4277-84. https://doi.org/10.1093/eurheartj/ehy626.

27. Mentz RJ, Kelly JP, von Lueder TG, Voors AA, Lam CSP, Cowie MR, et al. Noncardiac comorbidities in heart failure with reduced versus preserved ejection fraction. J Am Coll Cardiol. 2014;64: 2281-93. https://doi.org/10.1016/j.jacc.2014.08.036.

28. Andersen MJ, Borlaug BA. Heart failure with preserved ejection fraction: current understandings and challenges. Curr Cardiol Rep. 2014;16. https://doi.org/10.1007/s11886-014-0501-8. 
29. Gottdiener JS. Outcome of congestive heart failure in elderly persons: influence of left ventricular systolic function: the Cardiovascular Health Study. Ann Intern Med. 2002;137:631. https://doi.org/10.7326/0003-4819-137-8-200210150-00006.

30. van Empel V, Brunner-La Rocca H-P. Inflammation in HFpEF: key or circumstantial? Int J Cardiol. 2015;189:259-63. https://doi. org/10.1016/j.ijcard.2015.04.110.

31. Su M-YM, Lin L-Y, Tseng Y-HE, Chang C-C, Wu C-K, Lin J-L, et al. CMR-verified diffuse myocardial fibrosis is associated with diastolic dysfunction in HFpEF. JACC Cardiovasc Imaging. 2014;7:991-7. https://doi.org/10.1016/j.jcmg.2014.04.022.

32. Maruhashi T, Soga J, Fujimura N, Idei N, Mikami S, Iwamoto Y, et al. Endothelial function is impaired in patients receiving antihypertensive drug treatment regardless of blood pressure level: FMD-J study (Flow-Mediated Dilation Japan). Hypertension. 2017;70:790-7. https://doi.org/10.1161/HYPERTENSIONAHA. 117.09612.

33. Nair N, Gupta S, Collier IX, Gongora E, Vijayaraghavan K. Can microRNAs emerge as biomarkers in distinguishing HFpEF versus HFrEF? Int J Cardiol. 2014;175:395-9. https://doi.org/10. 1016/j.ijcard.2014.06.027.

34. Curl CL, Danes VR, Bell JR, Raaijmakers AJA, Ip WTK, Chandramouli $\mathrm{C}$, et al. Cardiomyocyte functional etiology in heart failure with preserved ejection fraction is distinctive - a new preclinical model. J Am Heart Assoc. 2018;7. https://doi.org/10. 1161/JAHA.117.007451.

35. Paulus WJ. $\mathrm{H}_{2}$ FPEF score: at last, a properly validated diagnostic algorithm for heart failure with preserved ejection fraction. Circulation. 2018;138:871-3. https://doi.org/10.1161/ CIRCULATIONAHA.118.035711 This study presents $\mathrm{H}_{2}$ FPEF and HFpEF nomogram-properly derived and validated diagnostic algorithms applicable in clinical practice and trials.

36. Sharma K, Kass DA. Heart failure with preserved ejection fraction: mechanisms, clinical features, and therapies. Circ Res. 2014;115:79-96. https://doi.org/10.1161/CIRCRESAHA.115. 302922 .

37. Zakeri R, Cowie MR. Heart failure with preserved ejection fraction: controversies, challenges and future directions. Heart. 2018;104:377-84. https://doi.org/10.1136/heartjnl-2016-310790.

38. Huis in 't Veld AE, de Man FS, van Rossum AC, Handoko ML. How to diagnose heart failure with preserved ejection fraction: the value of invasive stress testing. Neth Hear J. 2016;24:244-51. https://doi.org/10.1007/s12471-016-0811-0.

39.• Shah SJ. 20th Annual Feigenbaum Lecture: echocardiography for precision medicine-digital biopsy to deconstruct biology. J Am Soc Echocardiogr. 2019;32:1379-1395.e2. https://doi.org/10. 1016/j.echo.2019.08.002 This article presents the use of echocardiography as a "digital biopsy" of the heart, as well as the utility of machine learning.

40. Shah SJ, Aistrup GL, Gupta DK, O'Toole MJ, Nahhas AF, Schuster D, et al. Ultrastructural and cellular basis for the development of abnormal myocardial mechanics during the transition from hypertension to heart failure. Am J Physiol Heart Circ Physiol. 2014;306:H88-100. https://doi.org/10.1152/ajpheart. 00642.2013 .

41. Thomas L, Marwick TH, Popescu BA, Donal E, Badano LP. Left atrial structure and function, and left ventricular diastolic dysfunction. J Am Coll Cardiol. 2019;73:1961-77. https://doi.org/10. 1016/j.jacc.2019.01.059.

42. Oh JK, Hatle L, Tajik AJ, Little WC. Diastolic heart failure can be diagnosed by comprehensive two-dimensional and Doppler echocardiography. J Am Coll Cardiol. 2006;47:500-6. https://doi.org/ 10.1016/j.jacc.2005.09.032

43. Shah SJ, Kitzman DW, Borlaug BA, van Heerebeek L, Zile MR, Kass DA, et al. Phenotype-specific treatment of heart failure with preserved ejection fraction: a multiorgan roadmap. Circulation. 2016;134:73-90. https://doi.org/10.1161/CIRCULATIONAHA. 116.021884 .

44. Shah SJ, Katz DH, Deo RC. Phenotypic spectrum of heart failure with preserved ejection fraction. Heart Fail Clin. 2014;10:407-18. https://doi.org/10.1016/j.hfc.2014.04.008.

45. Lewis GA, Schelbert EB, Williams SG, Cunnington C, Ahmed F, McDonagh TA, et al. Biological phenotypes of heart failure with preserved ejection fraction. J Am Coll Cardiol. 2017;70:2186200. https://doi.org/10.1016/j.jacc.2017.09.006.

46. Cohen JB, Schrauben SJ, Zhao L, Basso MD, Cvijic ME, Li Z, et al. Clinical phenogroups in heart failure with preserved ejection fraction. JACC: Heart Failure. 2020;8:172-84. https://doi.org/10. 1016/j.jchf.2019.09.009.

47. Samson R, Jaiswal A, Ennezat PV, Cassidy M, Le Jemtel TH. Clinical phenotypes in heart failure with preserved ejection fraction. J Am Heart Assoc. 2016;5. https://doi.org/10.1161/JAHA. 115.002477.

48. Shah SJ, Katz DH, Selvaraj S, Burke MA, Yancy CW, Gheorghiade M, et al. Phenomapping for novel classification of heart failure with preserved ejection fraction. Circulation. 2015;131:269-79. https://doi.org/10.1161/ CIRCULATIONAHA.114.010637.

49. Wachter R, Edelmann F. Diagnosis of heart failure with preserved ejection fraction. Heart Fail Clin. 2014;10:399-406. https://doi. org/10.1016/j.hfc.2014.04.010.

50. Paulus WJ, Tschöpe C, Sanderson JE, Rusconi C, Flachskampf FA, Rademakers FE, et al. How to diagnose diastolic heart failure: a consensus statement on the diagnosis of heart failure with normal left ventricular ejection fraction by the Heart Failure and Echocardiography Associations of the European Society of Cardiology. Eur Heart J. 2007;28:2539-50. https://doi.org/10. 1093/eurheartj/ehm037.

51. Paulus WJ, Tschöpe C. A novel paradigm for heart failure with preserved ejection fraction. J Am Coll Cardiol. 2013;62:263-71. https://doi.org/10.1016/j.jacc.2013.02.092.

52. Gevaert AB, Boen JRA, Segers VF, Van Craenenbroeck EM. Heart failure with preserved ejection fraction: a review of cardiac and noncardiac pathophysiology. Front Physiol. 2019;10. https:// doi.org/10.3389/fphys.2019.00638.

53. Jia G, Hill MA, Sowers JR. Diabetic cardiomyopathy: an update of mechanisms contributing to this clinical entity. Circ Res. 2018;122: 624-38. https://doi.org/10.1161/CIRCRESAHA.117.311586.

54. Parasuraman SK, Loudon BL, Lowery C, Cameron D, Singh S, Schwarz K, et al. Diastolic ventricular interaction in heart failure with preserved ejection fraction. J Am Heart Assoc. 2019;8. https://doi.org/10.1161/JAHA.118.010114.

55. Tadic M, Cuspidi C, Frydas A, Grassi G. The role of arterial hypertension in development heart failure with preserved ejection fraction: just a risk factor or something more? Heart Fail Rev. 2018;23:631-9. https://doi.org/10.1007/s10741-018-9698-8.

56. Tam MC, Lee R, Cascino TM, Konerman MC, Hummel SL. Current perspectives on systemic hypertension in heart failure with preserved ejection fraction. Curr Hypertens Rep. 2017;19: 12. https://doi.org/10.1007/s11906-017-0709-2.

57. Lyle MA, Brozovich FV. HFpEF, a disease of the vasculature: a closer look at the other half. Mayo Clin Proc. 2018;93:1305-14. https://doi.org/10.1016/j.mayocp.2018.05.001.

58. Heinzel FR, Hohendanner F, Jin G, Sedej S, Edelmann F. Myocardial hypertrophy and its role in heart failure with preserved ejection fraction. J Appl Physiol. 2015;119:1233-42. https://doi.org/10.1152/japplphysiol.00374.2015.

59. Nadruz W, Shah AM, Solomon SD. Diastolic dysfunction and hypertension. Med Clin N Am. 2017;101:7-17. https://doi.org/ 10.1016/j.mena.2016.08.013. 
60. Kjeldsen SE, von Lueder TG, Smiseth OA, Wachtell K, Mistry N, Westheim AS, et al. Medical therapies for heart failure with preserved ejection fraction. Hypertension. 2020;75:23-32. https:// doi.org/10.1161/HYPERTENSIONAHA.119.14057.

61. Davis BR, Kostis JB, Simpson LM, Black HR, Cushman WC, Einhorn PT, et al. Heart failure with preserved and reduced left ventricular ejection fraction in the antihypertensive and lipidlowering treatment to prevent heart attack trial. Circulation. 2008;118:2259-67. https://doi.org/10.1161/ CIRCULATIONAHA.107.762229.

62. Jin C-N, Liu M, Sun J-P, Fang F, Wen Y-N, Yu C-M, et al. The prevalence and prognosis of resistant hypertension in patients with heart failure. PLoS One. 2014;9:e114958. https://doi.org/10.1371/ journal.pone.0114958.

63. Manolis AS, Manolis AA, Manolis TA, Melita H. Cardiac amyloidosis: an underdiagnosed/underappreciated disease. European Journal of Internal Medicine. 2019;67:1-13. https://doi.org/10. 1016/j.ejim.2019.07.022

64. Kapoor M, Rossor AM, Laura M, Reilly MM. Clinical presentation, diagnosis and treatment of TTR amyloidosis. J Neuromuscul Dis. 2019;6:189-99. https://doi.org/10.3233/JND-180371.

65. Siddiqi OK, Ruberg FL. Cardiac amyloidosis: an update on pathophysiology, diagnosis, and treatment. Trends in Cardiovascular Medicine. 2018;28:10-21. https://doi.org/10.1016/j.tcm.2017.07.004.

66. Alkhawam H, Patel D, Nguyen J, Easaw SM, Al-Sadawi M, Syed U, et al. Cardiac amyloidosis: pathogenesis, clinical context, diagnosis and management options. Acta Cardiol. 2017;72:380-9. https://doi.org/10.1080/00015385.2017.1335034.

67. Shin SC, Robinson-Papp J. Amyloid neuropathies. Mount Sinai Journal of Medicine: A Journal of Translational and Personalized Medicine. 2012;79:733-48. https://doi.org/10.1002/msj.21352.

68. Rapezzi C, Merlini G, Quarta CC, Riva L, Longhi S, Leone O, et al. Systemic cardiac amyloidoses: disease profiles and clinical courses of the 3 main types. Circulation. 2009;120:1203-12. https://doi.org/10.1161/CIRCULATIONAHA.108.843334.

69. Ando Y, Coelho T, Berk JL, Cruz MW, Ericzon B-G, Ikeda S, et al. Guideline of transthyretin-related hereditary amyloidosis for clinicians. Orphanet Journal of Rare Diseases. 2013;8:31. https:// doi.org/10.1186/1750-1172-8-31.

70. Yanagisawa A, Ueda M, Sueyoshi T, Okada T, Fujimoto T, Ogi Y, et al. Amyloid deposits derived from transthyretin in the ligamentum flavum as related to lumbar spinal canal stenosis. Mod Pathol. 2015;28:201-7. https://doi.org/10.1038/modpathol.2014.102.

71. Westermark P, Westermark GT, Suhr OB, Berg S. Transthyretinderived amyloidosis: probably a common cause of lumbar spinal stenosis. Ups J Med Sci. 2014;119:223-8. https://doi.org/10.3109/ 03009734.2014.895786.

72. Geller HI, Singh A, Alexander KM, Mirto TM, Falk RH. Association between ruptured distal biceps tendon and wild-type transthyretin cardiac amyloidosis. JAMA. 2017;318:962-3. https://doi.org/10.1001/jama.2017.9236.

73. Milandri A, Farioli A, Gagliardi C, Longhi S, Salvi F, Curti S, et al. Carpal tunnel syndrome in cardiac amyloidosis: implications for early diagnosis and prognostic role across the spectrum of aetiologies. Eur J Heart Fail. 2020;22:507-15. https://doi.org/10. 1002/ejhf. 1742

74. Sperry BW, Reyes BA, Ikram A, Donnelly JP, Phelan D, Jaber WA, et al. Tenosynovial and cardiac amyloidosis in patients undergoing carpal tunnel release. J Am Coll Cardiol. 2018;72:2040 50. https://doi.org/10.1016/j.jacc.2018.07.092.

75. Genova A, Dix O, Saefan A, Thakur M, Hassan A. Carpal tunnel syndrome: a review of literature. Cureus. 2020. https://doi.org/10. 7759/cureus.7333.

76. Sekijima Y, Uchiyama S, Tojo K, Sano K, Shimizu Y, Imaeda T, et al. High prevalence of wild-type transthyretin deposition in patients with idiopathic carpal tunnel syndrome: a common cause of carpal tunnel syndrome in the elderly. Hum Pathol. 2011;42: 1785-91. https://doi.org/10.1016/j.humpath.2011.03.004.

77. Maurer MS, Elliott P, Comenzo R, Semigran M, Rapezzi C. Addressing common questions encountered in the diagnosis and management of cardiac amyloidosis. Circulation. 2017;135: 1357-77. https://doi.org/10.1161/CIRCULATIONAHA.116. 024438 .

78. Di Giovanni B, Gustafson D, Delgado DH. Amyloid transthyretin cardiac amyloidosis: diagnosis and management. Expert Rev Cardiovasc Ther. 2019;17:673-81. https://doi.org/10.1080/ 14779072.2019.1662723.

79. Gopal DM, Ruberg FL, Siddiqi OK. Impact of genetic testing in transthyretin (ATTR) cardiac amyloidosis. Current Heart Failure Reports. 2019;16:180-8. https://doi.org/10.1007/s11897-019-00436-z.

80. Martinez-Naharro A, Treibel TA, Abdel-Gadir A, Bulluck H, Zumbo G, Knight DS, et al. Magnetic resonance in transthyretin cardiac amyloidosis. J Am Coll Cardiol. 2017;70:466-77. https:// doi.org/10.1016/j.jacc.2017.05.053.

81. Ruberg FL, Grogan M, Hanna M, Kelly JW, Maurer MS. Transthyretin amyloid cardiomyopathy. J Am Coll Cardiol. 2019;73:2872-91. https://doi.org/10.1016/j.jacc.2019.04.003.

82. Cappelli F, Baldasseroni S, Bergesio F, Perlini S, Salinaro F, Padeletti L, et al. Echocardiographic and biohumoral characteristics in patients with AL and TTR amyloidosis at diagnosis: AL and TTR amyloidosis characteristic. Clin Cardiol. 2015;38:69-75. https://doi.org/10.1002/clc.22353.

83. Maurer MS, Bokhari S, Damy T, Dorbala S, Drachman BM, Fontana M, et al. Expert consensus recommendations for the suspicion and diagnosis of transthyretin cardiac amyloidosis. Circ Heart Fail. 2019;12:e006075. https://doi.org/10.1161/ CIRCHEARTFAILURE.119.006075.

84. Gillmore JD, Maurer MS, Falk RH, Merlini G, Damy T, Dispenzieri A, et al. Nonbiopsy diagnosis of cardiac transthyretin amyloidosis. Circulation. 2016;133:2404-12. https://doi.org/10. 1161/CIRCULATIONAHA.116.021612.

85. Treglia G, Glaudemans AWJM, Bertagna F, Hazenberg BPC, Erba PA, Giubbini R, et al. Diagnostic accuracy of bone scintigraphy in the assessment of cardiac transthyretin-related amyloidosis: a bivariate meta-analysis. Eur J Nucl Med Mol Imaging. 2018;45:1945-55. https://doi.org/10.1007/s00259-018-4013-4.

86. Perugini E, Guidalotti PL, Salvi F, Cooke RMT, Pettinato C, Riva $\mathrm{L}$, et al. Noninvasive etiologic diagnosis of cardiac amyloidosis using 99m Tc-3,3-diphosphono-1,2-propanodicarboxylic acid scintigraphy. J Am Coll Cardiol. 2005;46:1076-84. https://doi. org/10.1016/j.jacc.2005.05.073.

87. Ilieşiu AM, Hodorogea AS. Treatment of heart failure with preserved ejection fraction. Adv Exp Med Biol. 2018;1067:67-87. https://doi.org/10.1007/5584_2018_149.

88. Yamamoto K. Pharmacological treatment of heart failure with preserved ejection fraction. Yonago Acta Med. 2017;60:71-6.

89. Kanwar M, Walter C, Clarke M, Patarroyo-Aponte M. Targeting heart failure with preserved ejection fraction: current status and future prospects. Vasc Health Risk Manag. 2016;12:129-41. https://doi.org/10.2147/VHRM.S83662.

90. Cleland JGF, Tendera M, Adamus J, Freemantle N, Polonski L, Taylor J, et al. The perindopril in elderly people with chronic heart failure (PEP-CHF) study. Eur Heart J. 2006;27:2338-45. https:// doi.org/10.1093/eurheartj/ehl250.

91. Massie BM, Carson PE, McMurray JJ, Komajda M, McKelvie R, Zile MR, et al. Irbesartan in patients with heart failure and preserved ejection fraction. N Engl J Med. 2008;359:2456-67. https://doi.org/10.1056/NEJMoa0805450.

92. Yusuf S, Pfeffer MA, Swedberg K, Granger CB, Held P, McMurray JJV, et al. Effects of candesartan in patients with chronic heart failure and preserved left-ventricular ejection 
fraction: the CHARM-Preserved Trial. Lancet. 2003;362:777-81. https://doi.org/10.1016/S0140-6736(03)14285-7.

93. Flather MD, Shibata MC, Coats AJS, Van Veldhuisen DJ, Parkhomenko A, Borbola J, et al. Randomized trial to determine the effect of nebivolol on mortality and cardiovascular hospital admission in elderly patients with heart failure (SENIORS). Eur Heart J. 2005;26:215-25. https://doi.org/10.1093/eurheartj/ ehi115.

94. Pitt B, Pfeffer MA, Assmann SF, Boineau R, Anand IS, Claggett $\mathrm{B}$, et al. Spironolactone for heart failure with preserved ejection fraction. N Engl J Med. 2014;370:1383-92. https://doi.org/10. 1056/NEJMoa1313731.

95. Solomon SD, McMurray JJV, Anand IS, Ge J, Lam CSP, Maggioni AP, et al. Angiotensin-neprilysin inhibition in heart failure with preserved ejection fraction. N Engl J Med. 2019;381:1609-20. https://doi.org/10.1056/NEJMoa1908655.

96. Borlaug BA, Anstrom KJ, Lewis GD, Shah SJ, Levine JA, Koepp GA, et al. Effect of inorganic nitrite vs placebo on exercise capacity among patients with heart failure with preserved ejection fraction: the INDIE-HFpEF randomized clinical trial. JAMA. 2018;320:1764-73. https://doi.org/10.1001/jama.2018.14852.

97. Nochioka K, Sakata Y, Miyata S, Miura M, Takada T, Tadaki S, et al. Prognostic impact of statin use in patients with heart failure and preserved ejection fraction:- a report from the CHART-2 study—. Circ J. 2015;79:574-82. https://doi.org/10.1253/circj. CJ-14-0865.

98. Tschöpe C, Van Linthout S, Kherad B. Heart failure with preserved ejection fraction and future pharmacological strategies: a glance in the crystal ball. Curr Cardiol Rep. 2017;19:70. https:// doi.org/10.1007/s11886-017-0874-6.

99. Kapelios CJ, Murrow JR, Nührenberg TG, Montoro Lopez MN. Effect of mineralocorticoid receptor antagonists on cardiac function in patients with heart failure and preserved ejection fraction: a systematic review and meta-analysis of randomized controlled trials. Heart Fail Rev. 2019;24:367-77. https://doi.org/10.1007/ s10741-018-9758-0.

100. Lamb YN, Deeks ED. Tafamidis: a review in transthyretin amyloidosis with polyneuropathy. Drugs. 2019;79:863-74. https://doi. org/10.1007/s40265-019-01129-6.

101. Maurer MS, Schwartz JH, Gundapaneni B, Elliott PM, Merlini G, Waddington-Cruz $\mathrm{M}$, et al. Tafamidis treatment for patients with transthyretin amyloid cardiomyopathy. N Engl J Med. 2018;379: 1007-16. https://doi.org/10.1056/NEJMoa1805689.

102. Fleg JL, Cooper LS, Borlaug BA, Haykowsky MJ, Kraus WE, Levine BD, et al. Exercise training as therapy for heart failure: current status and future directions. Circ Heart Fail. 2015;8:209 20. https://doi.org/10.1161/CIRCHEARTFAILURE.113.001420.

103. Pandey A, Kitzman DW, Brubaker P, Haykowsky MJ, Morgan T, Becton JT, et al. Response to endurance exercise training in older adults with heart failure with preserved or reduced ejection fraction. J Am Geriatr Soc. 2017;65:1698-704. https://doi.org/10. 1111/jgs. 14867.

104. Kosowski M, Kübler P, Kołodziej A, Krakowiak B, KustrzyckaKratochwil D, Sławin J, et al. InterAtrial Shunt Device (IASD®) implantation - a novel treatment method for heart failure with preserved ejection fraction. Kardiol Pol. 2017:736-41. https://doi. org/10.5603/KP.a2017.0096.

105. Kaye DM, Petrie MC, McKenzie S, Hasenfu $\beta$ G, Malek F, Post $\mathrm{M}$, et al. Impact of an interatrial shunt device on survival and heart failure hospitalization in patients with preserved ejection fraction. ESC Heart Fail. 2019;6:62-9. https://doi.org/10.1002/ehf2.12350.

106. Tsao CW, Lyass A, Enserro D, Larson MG, Ho JE, Kizer JR, et al. Temporal trends in the incidence of and mortality associated with heart failure with preserved and reduced ejection fraction. JACC Heart Fail. 2018;6:678-85. https://doi.org/10.1016/j.jchf.2018.03.006.
107. Kalogirou F, Forsyth F, Kyriakou M, Mantle R, Deaton C. Heart failure disease management: a systematic review of effectiveness in heart failure with preserved ejection fraction. ESC Heart Fail. 2020;7:195-213. https://doi.org/10.1002/ehf2.12559.

108. Shah SJ, Cogswell R, Ryan JJ, Sharma K. How to develop and implement a specialized heart failure with preserved ejection fraction clinical program. Curr Cardiol Rep. 2016;18:122. https://doi. org/10.1007/s11886-016-0802-1.

109. Roh J, Houstis N, Rosenzweig A. Why don't we have proven treatments for HFpEF? Circ Res. 2017;120:1243-5. https://doi. org/10.1161/CIRCRESAHA.116.310119.

110. Bhatia RS, Tu JV, Lee DS, Austin PC, Fang J, Haouzi A, et al. Outcome of heart failure with preserved ejection fraction in a population-based study. N Engl J Med. 2006;355:260-9. https:// doi.org/10.1056/NEJMoa051530.

111. Edelmann F. Epidemiology and prognosis of heart failure. Herz. 2015;40:176-84. https://doi.org/10.1007/s00059-015-4215-5.

112. Meta-analysis Global Group in Chronic Heart Failure (MAGGIC). The survival of patients with heart failure with preserved or reduced left ventricular ejection fraction: an individual patient data meta-analysis. Eur Heart J. 2012;33:1750-7. https://doi.org/10. 1093/eurheartj/ehr254.

113. Kontogeorgos S, Thunström E, Johansson MC, Fu M. Heart failure with preserved ejection fraction has a better long-term prognosis than heart failure with reduced ejection fraction in old patients in a 5-year follow-up retrospective study. Int J Cardiol. 2017;232:86-92. https://doi.org/10.1016/j.ijcard.2017.01.048.

114. Somaratne JB, Berry C, McMurray JJV, Poppe KK, Doughty RN, Whalley GA. The prognostic significance of heart failure with preserved left ventricular ejection fraction: a literature-based meta-analysis. Eur J Heart Fail. 2009;11:855-62. https://doi.org/10. 1093/eurjhf/hfp103.

115. Henning RJ. Diagnosis and treatment of heart failure with preserved left ventricular ejection fraction. World J Cardiol. 2020;12:7-25. https://doi.org/10.4330/wjc.v12.i1.7.

116. Chen S, Tang Y, Zhou X. Cystatin C for predicting all-cause mortality and rehospitalization in patients with heart failure: a metaanalysis. Biosci Rep. 2019;39. https://doi.org/10.1042/ BSR20181761.

117. Kasahara S, Sakata Y, Nochioka K, Yamauchi T, Onose T, Tsuji K, et al. Comparable prognostic impact of BNP levels among HFpEF, borderline HFpEF and HFrEF: a report from the CHART-2 study. Heart Vessel. 2018;33:997-1007. https://doi.org/10.1007/s00380018-1150-4.

118. Salah K, Stienen S, Pinto YM, Eurlings LW, Metra M, BayesGenis A, et al. Prognosis and NT-proBNP in heart failure patients with preserved versus reduced ejection fraction. Heart. 2019;105: 1182-9. https://doi.org/10.1136/heartjnl-2018-314173.

119. Sandesara PB, O'Neal WT, Kelli HM, Samman-Tahhan A, Hammadah M, Quyyumi AA, et al. The prognostic significance of diabetes and microvascular complications in patients with heart failure with preserved ejection fraction. Diabetes Care. 2018;41: 150-5. https://doi.org/10.2337/dc17-0755.

120. Carrasco-Sánchez FJ, Galisteo-Almeda L, Páez-Rubio I, Martínez-Marcos FJ, Camacho-Vázquez C, Ruiz-Frutos C, et al. Prognostic value of cystatin $\mathrm{C}$ on admission in heart failure with preserved ejection fraction. J Card Fail. 2011;17:31-8. https://doi. org/10.1016/j.cardfail.2010.07.248.

121. Tribouilloy C, Rusinaru D, Mahjoub H, Tartiere J-M, KesriTartiere L, Godard S, et al. Prognostic impact of diabetes mellitus in patients with heart failure and preserved ejection fraction: a prospective five-year study. Heart. 2008;94:1450-5. https://doi. org/10.1136/hrt.2007.128769.

122. Izumiya Y, Hanatani S, Kimura Y, Takashio S, Yamamoto E, Kusaka H, et al. Growth differentiation factor-15 is a useful prognostic marker in patients with heart failure with preserved ejection 
fraction. Can J Cardiol. 2014;30:338-44. https://doi.org/10.1016/ j.cjca.2013.12.010.

123. van Veldhuisen DJ, Linssen GCM, Jaarsma T, van Gilst WH, Hoes AW, Tijssen JGP, et al. B-type natriuretic peptide and prognosis in heart failure patients with preserved and reduced ejection fraction. J Am Coll Cardiol. 2013;61:1498-506. https://doi.org/ 10.1016/j.jacc.2012.12.044.

124. Kang S-H, Park JJ, Choi D-J, Yoon C-H, Oh I-Y, Kang S-M, et al. Prognostic value of NT-proBNP in heart failure with preserved versus reduced EF. Heart. 2015;101:1881-8. https://doi.org/10. 1136/heartjnl-2015-307782.

125. Burke MA, Katz DH, Beussink L, Selvaraj S, Gupta DK, Fox J, et al. Prognostic importance of pathophysiologic markers in patients with heart failure and preserved ejection fraction. Circ Heart Fail. 2014;7:288-99. https://doi.org/10.1161/ CIRCHEARTFAILURE.113.000854.

126. Quirós López R, García Alegría J, Martín Escalante MD, Trujillo Santos J, Villena Ruiz MÁ, Perea ME. Factores pronósticos y supervivencia a largo plazo tras el diagnóstico inicial de insuficiencia cardiaca. Med Clin. 2012;138:602-8. https://doi. org/10.1016/j.medcli.2011.03.031.

Publisher's Note Springer Nature remains neutral with regard to jurisdictional claims in published maps and institutional affiliations. 